\title{
Reproductive Growth and Development of Blueberry'
}

\author{
J. G. Williamson, D. A. Phillips, J. W. Olmstead, and P. M. Lyrene
}

\section{Flower Bud Initiation, Fruit Development, and Yield}

One of the most important developmental processes occurring in blueberry fields during late summer and fall is flower bud initiation and development. During vegetative growth, one bud develops on the stem for each leaf that is produced. The bud is located just above the point where the petiole meets the stem (leaf axil). These axillary buds are vegetative when they first develop. Depending on day length, temperature, and plant health, some of them will convert to flower buds during the late summer and fall. Flower buds develop first on the older current-season's wood that grew during the spring, and last on the vigorous upright growth that develops after postharvest pruning. As flower buds develop, they become larger and rounder and can easily be distinguished from vegetative buds during December and January (Figure 1).

Research has shown that the conversion of vegetative buds to flower buds is controlled by day length and temperature. Day length is measured by special plant pigments within the leaves and buds. As days shorten during the fall, vegetative buds gradually convert to flower buds. Experiments have shown that high temperatures reduce flower bud initiation, even when days are short enough to induce it. Moreover, flower buds initiated under high temperatures are smaller and do not develop as well as those initiated under lower temperatures.

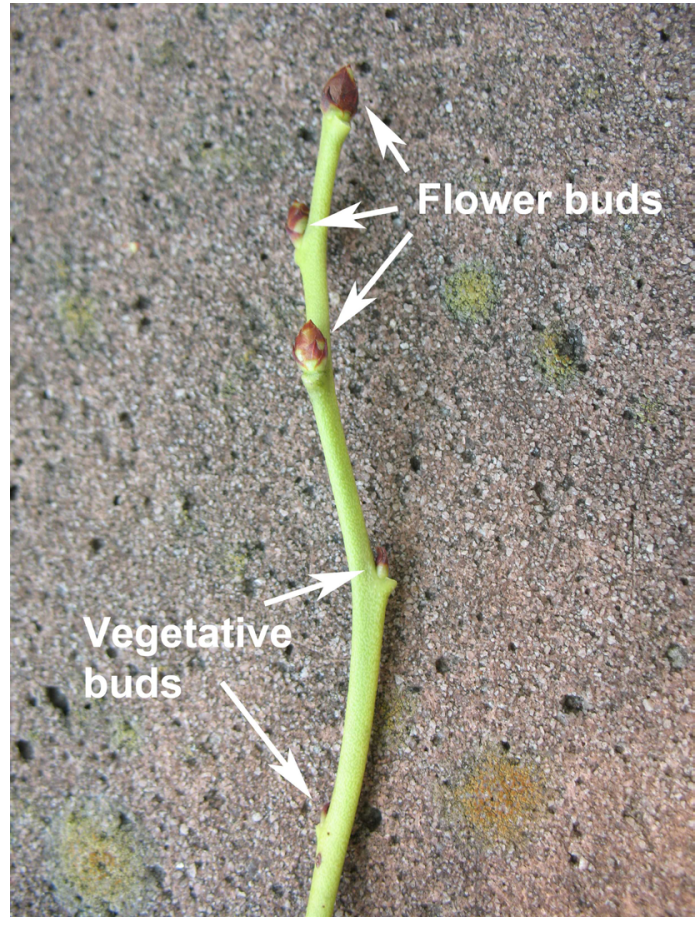

Figure 1. Blueberry shoot with vegetative and flower buds Credits: Jeffrey G. Williamson and James W. Olmstead, UF/IFAS

Blueberry leaves are the major organs that produce photosynthates and perceive changes in day length. They are therefore extremely important for flower bud initiation and development. Research has shown that southern highbush blueberry leaves must remain healthy and attached at least through early November in Florida for good flower bud

1. This document is HS976, one of a series of the Horticultural Sciences Department, UF/iFAS Extension. Original publication date April 2004. Revised June 2015, July 2018, and March 2020. Visit the EDIS website at http://edis.ifas.ufl.edu.

2. J. G. Williamson, professor; D. A. Phillips, blueberry Extension coordinator; J. W. Olmstead, former assistant professor; and P. M. Lyrene, professor emeritus; Horticultural Sciences Department; UF/IFAS Extension, Gainesville, FL 32611.

The use of trade names in this publication is solely for the purpose of providing specific information. UF/IFAS does not guarantee or warranty the products named, and references to them in this publication do not signify our approval to the exclusion of other products of suitable composition. All chemicals should be used in accordance with directions on the manufacturer's label. Use pesticides safely. Read and follow directions on the manufacturer's label.

The Institute of Food and Agricultural Sciences (IFAS) is an Equal Opportunity Institution authorized to provide research, educational information and other services only to individuals and institutions that function with non-discrimination with respect to race, creed, color, religion, age, disability, sex, sexual orientation, marital status, national origin, political opinions or affiliations. For more information on obtaining other UF/IFAS Extension publications, contact your county's UF/IFAS Extension office. U.S. Department of Agriculture, UF/IFAS Extension Service, University of Florida, IFAS, Florida A \& M University Cooperative Extension Program, and Boards of County Commissioners Cooperating. Nick T. Place, dean for UF/IFAS Extension. 
initiation and development. When plants defoliate prematurely in the fall, flower bud number is greatly reduced and flower bud development is impaired (Figures 2 and 3).

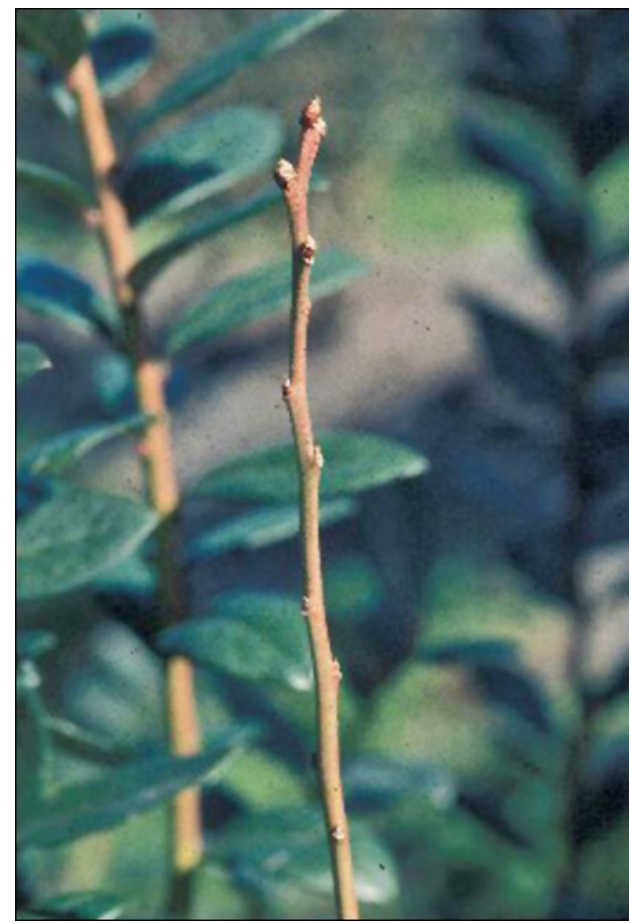

Figure 2. Blueberry cane that was defoliated in mid-September has very few well-developed flower buds later in the winter. Credits: Jeffrey G. Williamson, UF/IFAS

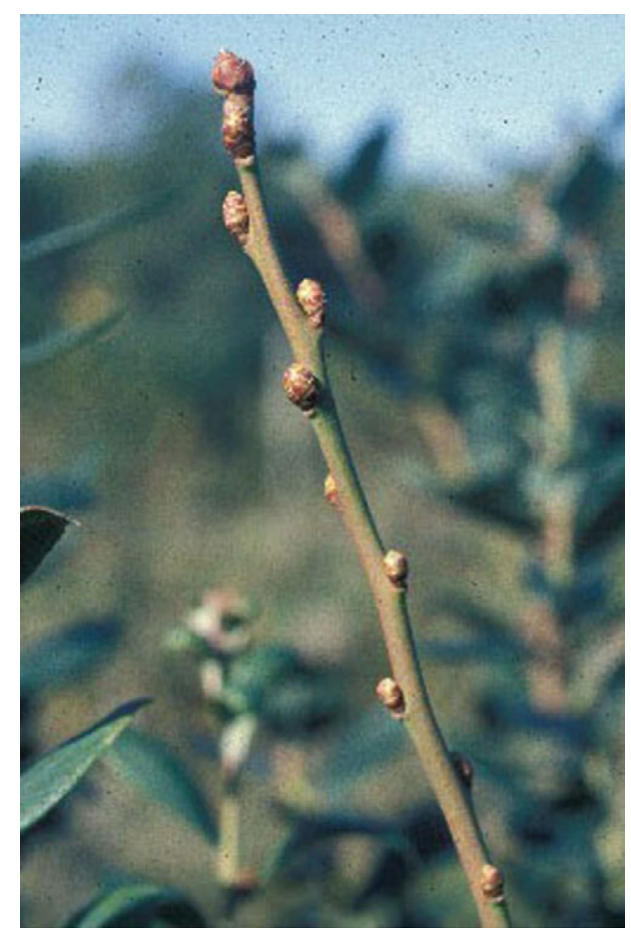

Figure 3. Blueberry cane that retained its leaves through early November has a full complement of flower buds. Credits: Jeffrey G. Williamson, UF/IFAS
Preventing early fall defoliation requires proper fertilization, summer pruning, and a judicious summer disease management program to control leaf spot diseases. Frequent, light fertilizer applications throughout the summer are needed for growth of new, fruit-bearing wood and for leaf retention into the fall. However, excessive late summer or fall fertilization may delay cessation of terminal growth and reduce or delay flower bud formation (see Nutrition and Fertilization Practices for Southern Highbush Blueberry in Florida [https://edis.ifas.ufl.edu/hs1356]). Postharvest pruning to promote new, healthy shoots and fungicide applications to protect the new growth are extremely important cultural practices to maintain healthy foliage into the fall for flower bud initiation and development (Figures 4 and 5). See Pruning Southern Highbush Blueberry in Florida (https://edis.ifas.ufl.edu/hs1359).

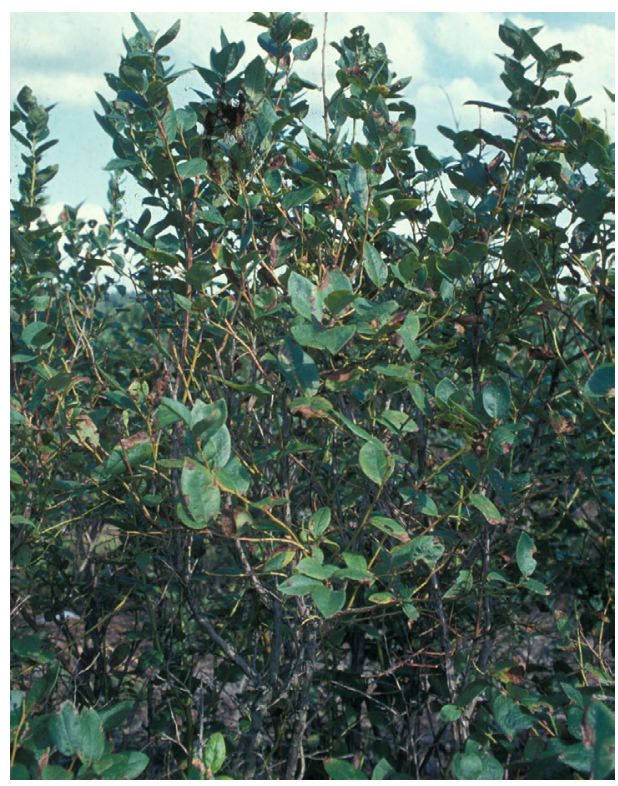

Figure 4. Nonpruned blueberry plant showing weak summer growth and early fall defoliation in September.

Credits: Jeffrey G. Williamson, UF/IFAS

Using drip or microjet irrigation instead of overhead irrigation reduces leaf wetting and likely reduces the incidence of leaf diseases that can cause early defoliation. For overhead irrigation systems, it is generally best to irrigate in the early morning so that leaves dry quickly. Consult the Florida Blueberry Leaf Disease Guide (https://edis.ifas.ufl.edu/ pp348) and Florida Blueberry Integrated Pest Management Guide (http://edis.ifas.ufl.edu/hs380) for more information about controlling leaf spot diseases.

A proper balance of vegetative and reproductive buds is required to maximize yields of high-quality fruit (Figure 6). If there are too few flower buds, then the yield potential will not be maximized. If there are too many flower buds relative to the number of vegetative buds, the number of 
berries may exceed what can be supported by the bush. The result could be poor leafing, small berries, delayed harvest, poor fruit quality, and plant stress or even death. In some cases, especially with high-yielding southern highbush cultivars, detailed dormant pruning may be needed to thin crop loads to achieve good fruit quality and earliness.

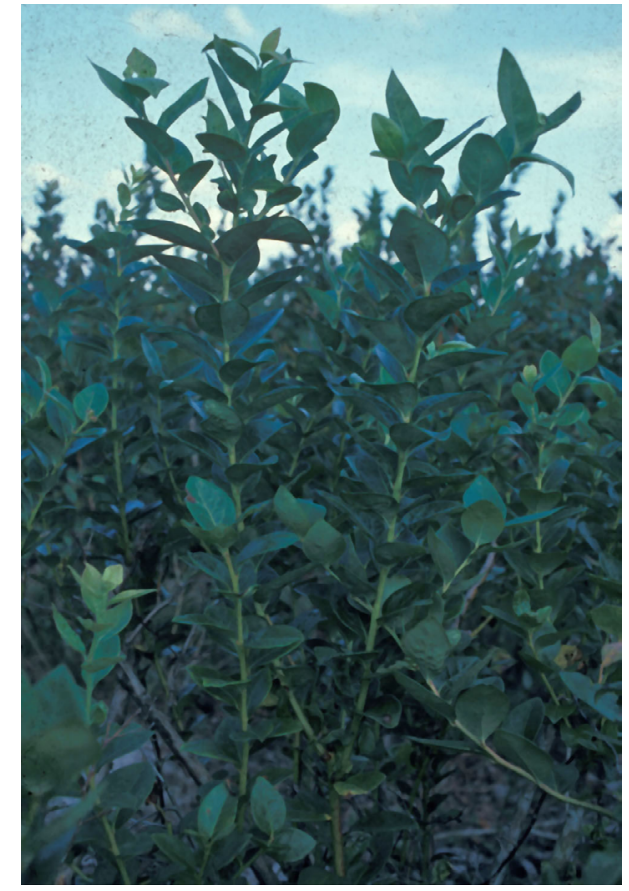

Figure 5. Summer-pruned blueberry plant showing a vigorous summer growth of flush and healthy leaves entering the fall season. Credits: Jeffrey G. Williamson, UF/IFAS

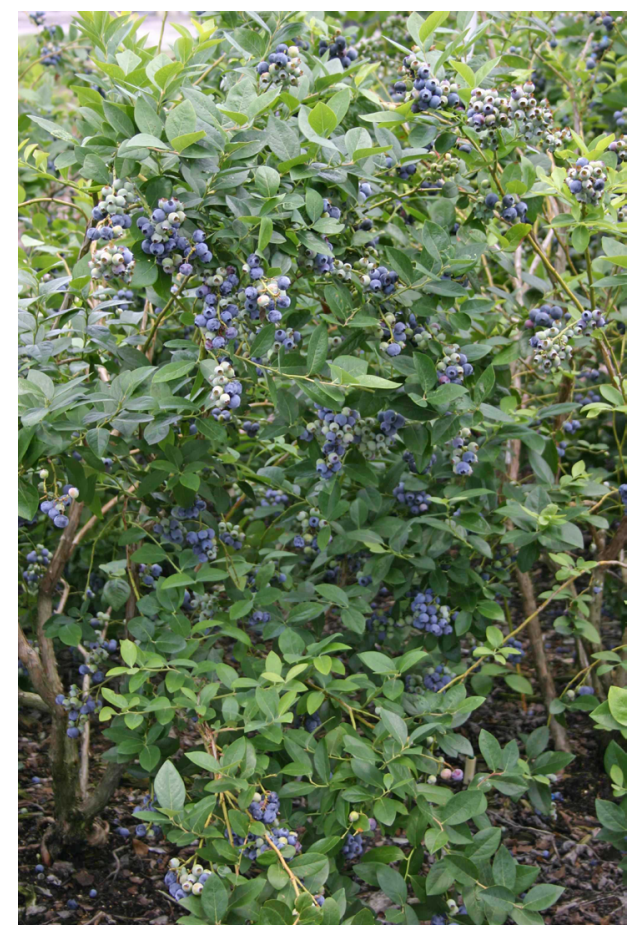

Figure 6. A proper balance of berries and leaves is needed to produce high yields of high-quality berries for the early market. Credits: Jeffrey G. Williamson, UF/IFAS

\section{Plant Growth Regulators}

Plant growth regulators (PGRs) are synthetic or naturally occurring compounds that can be used to modify plant growth and/or development processes, such as flowering, fruit set, fruit ripening, branching, and fruit and leaf abscission. Plant responses to PGR applications are often inconsistent and unpredictable. This is because PGRs are usually effective at very low concentrations, and they must be precisely delivered to specific tissues (sites) in plants at the right stages of plant growth. Too much or too little PGR, or a PGR applied at the wrong stage of plant growth and development, will not result in the desired growth response and, in fact, may result in undesirable responses. Because PGRs must be absorbed by plant tissues, environmental conditions at the time of application play an important and often underappreciated role in treatment efficacy. As with pesticides, blueberry growers should read and follow all label instructions when using PGRs.

\section{Hydrogen Cyanamide (Dormex ${ }^{\circledast} /$ BudPro ${ }^{\circledast} /$ Krop-Max $^{\circledast}$ )}

Certain southern highbush cultivars in the deciduous production system exhibit slow or delayed leaf development as they emerge from dormancy. This can result in delayed fruit ripening and cause stress to plants that set a heavy crop but have poor or delayed leaf canopy development. Hydrogen cyanamide $(\mathrm{HC})$ is a plant growth regulator that may be a useful tool for stimulating earlier and stronger spring leafing of certain deciduous southern highbush cultivars in Florida. On responsive cultivars where spring leafing is significantly advanced by $\mathrm{HC}$, the harvest season is often earlier and more concentrated than would otherwise occur. Increased berry weight (size) and a slight increase in total yield have also been noted in some cases, but the main advantages are earlier and more concentrated berry harvests.

Hydrogen cyanamide is classified as a restricted-use pesticide with specific requirements for its safe and legal application, including very specific requirements for protective gear and specialized spray equipment (e.g., an enclosed tractor cab). Most Florida blueberry growers who use the deciduous system to produce for the early-season fresh-fruit market will want to consider using HC. Growers who may not be interested in this product include organic growers, U-pick, rabbiteye, and other small, locally based growers who are not targeting the early market, as well as growers who use an "evergreen" or "nondormant" production system. Growers who are considering using HC should first become familiar with the product's label and 
the requirements and restrictions therein. Small-acreage growers who do not have the expertise or equipment necessary for safe and proper application may find it easier to have $\mathrm{HC}$ custom applied by a certified professional pesticide applicator who has experience with this product. All chemicals should be used in accordance with the directions on the manufacturer's label. Use all chemical products safely.

\section{Hydrogen Cyanamide Rates}

If misapplied, $\mathrm{HC}$ has the potential to damage flower buds. Therefore, it is very important to follow the label directions exactly. Product labels typically provide a range of application rates. Higher rates may aid in burning off last year's foliage (as with, for example, the Dormex label). However, the potential for crop injury is increased at higher rates. Research and grower experience in Florida have shown that as $\mathrm{HC}$ application rates increase, so does the potential for flower bud injury. Apart from rate, $\mathrm{HC}$ injury is also dependent on cultivar, weather conditions, pre-chilling conditioning, and possibly other unknown factors. A safe and effective spray concentration for most situations in Florida with HC-tolerant cultivars and adequate winter chilling preconditioning appears to be $1.5 \%(\mathrm{v} / \mathrm{v})$ of formulated product applied with enough spray volume to provide thorough coverage. However, sensitive cultivars such as 'Jewel' and 'Primadonna' have been damaged by this and lower rates, especially following mild winters with low chill accumulation prior to treatment. This is particularly true in central and south-central Florida, where winter chill accumulation is more likely to be low (see Timing Hydrogen Cyanamide Applications below). The effect of $\mathrm{HC}$ is localized on plants; therefore, thorough coverage is essential for a uniform response.

\section{Timing Hydrogen Cyanamide Applications}

Applications should be made 30 or more days prior to natural bud break (be sure to follow the label directions). Hydrogen cyanamide should be applied only to fully dormant plants, and is most effective when applied to plants that have been exposed to significant winter chilling before treatment. In Alachua County during a typical winter, this combination of events usually occurs between mid-December and early January. Blueberry fields to be treated with $\mathrm{HC}$ should be carefully monitored as to the onset of dormancy, chill accumulation, and the timing of natural bud break, which vary from year to year and from one location to another in Florida. Hence, the timing of HC applications should be based on plant condition, weather, and anticipated date of natural bud break rather than the calendar date.

Generally, applications of $\mathrm{HC}$ to plants that have received little or no chilling are not as effective, and more stem and flower bud injury has been observed. This is generally a greater problem in central and south-central Florida where chilling is more often limited than it is in north or north-central Florida. This emphasizes the importance of restricting applications of $\mathrm{HC}$ to the dormant period when some chilling has occurred, but before flower bud development has progressed past stage 2 (before flower bud scales begin to separate; Figure 7). This scenario may be difficult to achieve some years in central and south-central Florida, especially during mild winters when chilling is limited and early flowering occurs. Delaying applications too long (after the majority of flower buds have passed stage 2 in their development; Figure 8) may result in serious flower bud damage and yield reduction. Thus, the application time for maximum benefit of HC is highly dependent on winter weather, plant conditioning, and the stage of plant development.

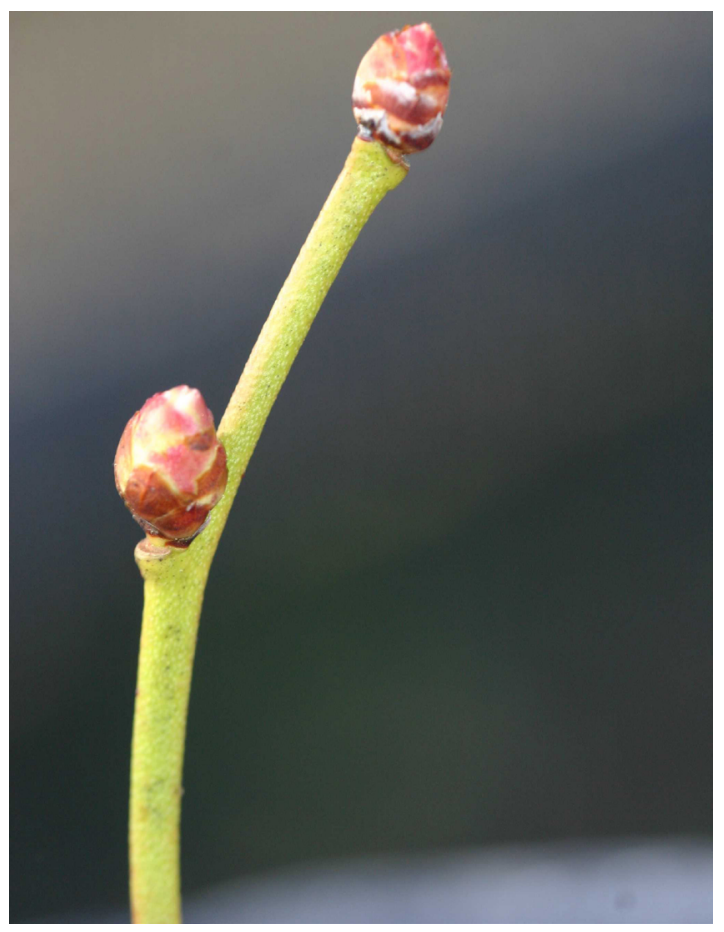

Figure 7. Flower bud developmental stage 2: The flower bud is swollen with bud scales still closed. For HC-tolerant cultivars, HC can usually be safely sprayed at this stage of development.

Credits: Jeffrey G. Williamson, UF/IFAS 


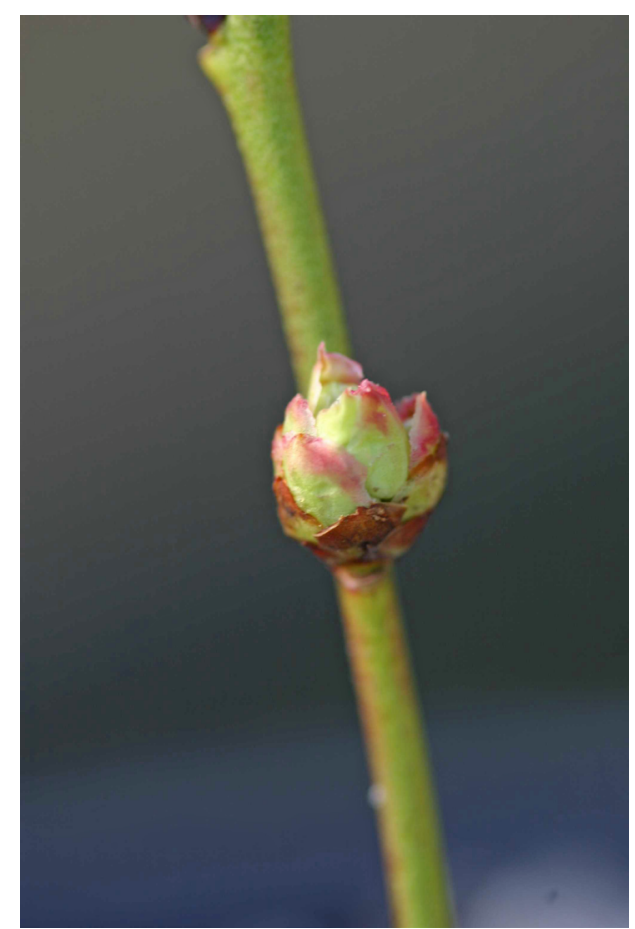

Figure 8. Flower bud developmental stage 3: Bud scales have separated, exposing interior parts of the bud. Flower bud injury may occur from hydrogen cyanamide sprays at this stage and more advanced developmental stages.

Credits: Jeffrey G. Williamson, UF/IFAS

\section{Cultivar Response to Hydrogen Cyanamide}

Cultivar response to $\mathrm{HC}$ is an important consideration and one for which information is still being developed. Cultivars that potentially benefit the most from HC applications are those that bear heavy crops and/or naturally have slow or weak leaf expansion and shoot growth in the spring. Alternatively, cultivars that leaf well in the spring while carrying a medium to heavy crop load may benefit little if at all from HC applications. Hydrogen cyanamide can be safely applied to numerous cultivars in Florida; however, individual cultivars vary in their sensitivity to $\mathrm{HC}$. When the tolerance to $\mathrm{HC}$ is not known, it should be tested and evaluated on specific cultivars prior to large-scale use. Cultivars that have shown greater than average sensitivity to HC in Florida include 'Windsor,' 'Primadonna', 'Jewel', and 'Optimus'. When applied correctly under suitable conditions, the potential benefits of $\mathrm{HC}$ include strong spring bud break and vegetative growth, shorter fruit development periods with earlier and more concentrated harvest periods, and sometimes modest increases in berry weight (size) and yield. These benefits are generally more prevalent on varieties that are naturally slow or weak to leaf out in the spring. The concentrated bloom and harvest periods and shortened fruit development periods obtained with HC could potentially help with disease and insect control and may reduce the number of annual pesticide applications needed in Florida blueberries. On the other hand, when applied incorrectly, HC can result in flower bud injury, excessive fruit thinning, and yield reductions.

\section{Gibberellic Acid (GA)}

Gibberellic acid $\left(\mathrm{GA}_{3}\right)$ is a naturally occurring PGR that can influence the fruit set of many crops, including blueberry. $\mathrm{GA}_{3}$ is not recommended for use on southern highbush blueberries in Florida because it may cause excessive fruit set, which results in plant stress and poor-quality, late-ripening berries. Fruit drop of rabbiteye berries is a perennial problem and can significantly reduce yields. Following petal fall, unfertilized berries may look normal for 1 or 2 weeks. However, berries that are 1/8 inch or less in diameter at 2-2 1/2 weeks after petal fall usually begin to drop. The berry normally detaches at the point where the pedicel attaches to the raceme. One way to minimize fruit drop following inadequate pollination is to apply $\mathrm{GA}_{3}$ (trade name $=$ ProGibb $^{\oplus}$ ) during bloom. During normal pollination, developing seeds synthesize gibberellins. The application of $\mathrm{GA}_{3}$ during and immediately after bloom mimics this natural process. The increase in rabbiteye blueberry fruit set from $\mathrm{GA}_{3}$-treated plants over untreated plants depends on how much natural fruit set is achieved. Under conditions of high natural fruit set, the increase in fruit set from $\mathrm{GA}_{3}$ application is of no practical benefit. When natural fruit set is low, $\mathrm{GA}_{3}$ could increase fruit set and yield substantially.

In addition to increasing fruit set and yield, $\mathrm{GA}_{3}$ applications consistently decrease average berry weight (size) and increase the fruit development period. The decrease in average berry weight appears to be a direct effect of $\mathrm{GA}_{3}$ application and not merely a response to heavier crop loads. The increase in the fruit development period from $\mathrm{GA}_{3}$ application varies with year and cultivar, but $\mathrm{GA}_{3}$ application can delay harvest by 5-15 or more days, which may necessitate a change in marketing strategies.

For rabbiteye fields that have a history of low-percent fruit set, current recommendations call for an initial GA 3 application when $40 \%-50 \%$ of the flowers have opened and been visited by bees. About $10 \%$ of the petals should have fallen. A second application should be made approximately 10-18 days later. When two cultivars with different bloom dates are planted together, good results may be obtained by spraying alternate rows of different cultivars and directing the treatment at the cultivar in bloom. Under this method, four spray applications can be used. The total amount applied at each application is 20 grams of active ingredient 
(a.i.) per acre because the sprayer targets only alternate rows or the equivalent each time. The sprays are usually spaced about 10 days apart. The first and second sprays are directed at the first cultivar to bloom. Some $\mathrm{GA}_{3}$ will also reach the adjacent cultivar and help the early flowers to set fruit. The third and fourth sprays are directed toward the later-blooming cultivar. The last flowers to open in the early-flowering cultivar will receive spray drift from the last two sprays. The total amount of $\mathrm{GA}_{3}$ applied for the season should not exceed the recommended label rate. Night applications increase the drying time and may increase $\mathrm{GA}_{3}$ absorption and effectiveness. If possible, growers should not apply $\mathrm{GA}_{3}$ within 18 hours of rain.

The greatest benefits to fruit set from $\mathrm{GA}_{3}$ application are obtained under conditions of low natural fruit set. Growers should assess the potential for fruit set on their particular farm (overlapping bloom of pollinizers, population and activity of bees, weather, etc.) when deciding whether or not to apply $\mathrm{GA}_{3}$. Although $\mathrm{GA}_{3}$ may increase fruit set and yield of rabbiteye blueberry, it may also delay fruit maturity and decrease average berry size. Because of the high costs and possible negative effects of $\mathrm{GA}_{3}$ application, growers with fruit set problems should examine why their fields are not being pollinated properly. Increasing the bee population, managing bees better in the field, and controlling flower thrips can often reduce problems with fruit set. In Florida, $\mathrm{GA}_{3}$ is limited to use on large rabbiteye plantings that suffer from inadequate natural pollination. 